\title{
Usual and unusual maps: a playful introduction to the basic concepts of cartography in high school
}

DOI: $10.46932 / \mathrm{sfjdv2n1-053}$

Received in: November 1st, 2020

Accepted in: December 30th, 2020

\section{Érico Anderson de Oliveira}

CEFET - MG

E-mail: ericoliv@cefetmg.br

Mariana da Silva Ferreira

E. E. de Pedro Leopoldo - MG

E-mail: marianamsf@yahoo.com.br

\section{Rosália C. Sanábio de Oliveira CEFET-MG \\ E-mail: rsanabio@cefetmg.br}

\author{
Viviane Moreira Maciel \\ Colégio Cavalieri - MG \\ E-mail: vmmoreiraviviane@gmail.com
}

\begin{abstract}
This work aims to show the feasibility of introducing basic cartographic concepts in the first year of high school, with simple resources, contributing to the process of knowledge construction by the young person himself by stimulating his curiosity. For this, a theoretical study was made on the theme presented here, then activities were given in the classroom and, later, the diagnosis and debate of the results obtained were carried out. Cartographic literacy, demonstrated in these activities, predisposes the student to work his competence in this form of language, qualifying him/her to make multiple readings of the world through the most disparate cartographic representations possible. Thus, after the didactic sequence used in mediation with the students, in addition to encouraging the reading of maps, the subjects also had the opportunity to create their own fantasy maps. The work was based on David Ausubel's Theory of Significant Learning and the parameters present also in Lev Vygotsky's Historical-Cultural Theory and Henri Wallon's Theory of Development were also used.
\end{abstract}

Keywords: David Ausubel, teaching geography, geography and playfulness, cartography, fantasy maps.

\section{INTRODUCTION}

When the teacher carries out his planning, it is essential that he meditate on what he wants his student to assimilate with that chosen practice; whether this will be motivated, impelled in the search for new discoveries; skills and competences will be recognized and intensified. Finally, as that educational practice will favor the learning of that individual. Instruction and its process grant the subject the constant creation of new relationships, absorbing, organizing and reformulating what he has seized, because cognition is impermanent and constantly transmutes. 
The contents presented at the school should ensure that the student correlates this knowledge with his own life, with his previous knowledge and his predilections, if possible. Starting from this purpose, students of the 1st year of high school, at the beginning of the bimester, were encouraged to individually build fantasy maps, that is, maps elaborated from a history already known or created by them. However, it was not enough just to produce the maps within a scenario and a story, because it was necessary to present and justify their singularities, to give them an essence. Later, they would have to search for maps located in libraries, websites or repositories on the internet, choose one to their liking, print it and bring it to class on the agreed date.

In implementing their projects, the students, based on their previous knowledge, the investigations made, the inquiries and the analyses of the documentary assisted on cartography and the complementary material prepared by the teacher, began to understand the importance of cartography for the teaching of geography and for human development. They made the connections between the knowledge of the territory and the survival of primitive man with the first guides, as well as the advancement and potentialities of geographic technologies for the teaching of maps to date.

Permeating these observations, others were made as to: the control of cartographic technology in each epoch, the use of this by the powers for the conquest of territories and the appropriation of natural wealth, oppression and fragmentation of space, the increase of inequalities until we reach the globalization of information in contemporaneity. That is, those involved were able to capture that the maps are historical-social compositions, portray the places, cultures and experiences that occurred in the landscapes portrayed, and, therefore, are personifications dating from reality, imaginary and also mystification, never being exempt from value judgment.

We then used the precepts suggested by David Ausubel's Theory of Significant Learning (2000). In it the progress in the student's learning happens according to their cognitive development, as it evolves. There is concern about the processes of understanding the world by the individual, with the alteration of these perceptions and their levels of deepening. This theoretical foundation is connected with the foundations of constructivist philosophy that understands knowledge as a diligent phenomenon, in motion. It is based on the certainty that we project our reality through the impressions and inquiries arising from our own existences. In harmony with this perspective, learning occurs through attempts to solve problems, through errors and correct answers and equivalent deductions.

Thus, new data and information can be studied and fixed to the extent that relevant and comprehensive concepts are conveniently clarified and accessible in the cognitive structure of the individual and thus help in the elaboration of new principles and convictions.

Ausubel (1980) clearly defines what significant learning and retention would be ahead: 
Learning by meaningful reception mainly involves the acquisition of new meanings from presented learning material. It requires either a meaningful learning mechanism or the presentation of potentially significant material to the learner. In turn, the last condition presupposes (1) that the learning material itself may be related in a non-arbitrary (plausible, sensitive and non-random) and not literal way with any appropriate and relevant cognitive structure (i.e., which has 'logical' meaning) and (2) that the apprentice's particular cognitive structure contains relevant anchored ideas, with which the new material can be related. (AUSUBEL,1980, p. 1)

Thus, the interaction between new potential concepts and relevant ideas in the cognitive structure of the learner gives rise to true meanings. Because the cognitive structure of each apprentice is unique, all new meanings acquired are also necessarily unique.

We chose to elaborate a complementary didactic material to ascertain whether the cartographic views had been achieved in the previous grade - the 9th year of elementary school and the other materials were created by the students during the follow-up of the practice. The idea for these threads of activities started from the desire to link the cartographic contents necessary for the teaching of Geography for the series with the declared fascination of the students for books / games / fantastic or imaginary stories. For the students, these dynamics related to maps have become genuinely significant actions and, for this reason, with the related topics being easily assimilated.

Consequently, the student in this course is not passive in the evolution of his learning and, in addition to this, we have efforts made by the teacher such as the idealization and preparation of significant teaching material for the student, pertinent methodology, among other aspects, as again Ausubel (1980) clarifies:

(...) in any discipline the cognitive structure of the apprentice can be influenced (1) in a substantive way, through the inclusive character, the power of explanation and the integrative properties of the specific and unifying concepts and principles presented to the learner; and (2) systematically, through appropriate methods of presentation, disposition and evaluation of the significant acquisition of the subject, through the appropriate use of organized and pre-tested instruction material and through the proper manipulation of both cognitive and social variables of personality motivation. (AUSUBEL,1980, p. 10)

Taking the precepts of Ausubel (2000), we plan a methodology focused on the student, seeking to dynamically enable self-learning, favoring group work, decision-making in the face of the choices defined by them, the search for problem solving and the adoption of a questioning position in the face of reality, that is, all factors that together enable the emergence of meaningful learning. This is nothing more that students can build their own knowledge in a system in which, when trying to decide, judge and define new processes, they actually learn, managing to situate themselves and elucidate the issues that manifest themselves before them.

Moreover, during the work, the students found that learning can come along with affection and joy, both derived from the explorations undertaken and the freedom to make choices, previously defined 
collectively between teacher and students. Through the various activities carried out, there was a reinforcement in the literacy of cartographic definitions - which the student brought from elementary school.

Simple activities, which is not to say that they are simplistic, can make learning basics of cartography more interesting and stimulating. The realization of these must be linked to the conception of appropriate teaching strategies, with theoretical contributions to the teacher's choice as the basis of these performances.

\section{OBJECTIVE}

In a discipline such as Geography, as important as what will be the contents to be worked on in the classroom and the objectives implicit in these choices, we must recognize the crucial importance of the didactics of this curricular component that allows us to build our teaching strategies and understand how the cognitive development of the student takes place. Moreover, it enables the educator's discernment about the evolution in the student's learning according to their age group and the degree of education, of course, also taking into account the particularities of each of them.

In the teaching of Geography, cartography is a precious tool that provides the reading of the world by different languages: written, oral, graphic, symbolic, iconic, numerical, digital... These languages are distinct means of transmitting knowledge, but the value in the use of these is the breadth of the messages they bring with them, as well as the ability that the student will have to decipher, recognize, translate the messages, making them indispensable for himself and others.

The National Curriculum Parameters (PCN ) of Geography from the 6th to the 9th grade, emphasize the dimension of cartography for the teaching and learning of this curricular component in the classroom, as a mechanism for reading the world and places:

From cartographic literacy to critical reading and conscious mapping Cartographic literacy comprises a series of learnings necessary for students to continue their training in the elements of graphic representation already initiated in the first two cycles to later work with cartographic representation. The continuity of work with cartographic literacy should consider the interest that children and young people have in images, a fundamental attitude in cartographic learning. The drawings, the photos, the models, the plants, the maps, the satellite images, the figures, the tables, the games, finally everything that represents the visual language remains the materials and work products that the teacher must use at this stage. But to achieve the goals of cartographic literacy, all these resources must be examined and students must find meanings, stimulating the search for information that the images contain. (...) The student needs to grasp the basic elements of the graphic/cartographic representation so that he can effectively read the map. (PCN, 1998, p. 76).

In turn, the National Curriculum Guidelines for High School (BRASIL, 2006, volume 3, p. 50) also consider the magnitude of cartographic language for the teaching of Geography: 
The cartographic concepts (scale, legend, cartographic alphabet) and geographical concepts (location, nature, society, landscape, region, territory and place) can be perfectly constructed from everyday practices. In fact, it is a question of reading the experience of the place in relation to a set of concepts that structure geographic knowledge, including the categories space and time. When working with cartographic and geographic concepts, having as interface the categories of space and time, we must incorporate other components that will serve as curricular references for high school, that is, admit the diversity of sources and languages, valuing the objective and subjective readings of the world. (BRASIL, 2006, v. 3, p. 50).

Thus, cartography and its language consist of a instigating and fundamental didactic alternative, a consistent methodological bias to be considered daily in geography teaching practice. It is not satisfactory just to orient yourself and locate yourself in space, recognizing where the individual is spatially, it is necessary to behave as a subject and go beyond.

In this perspective, as teachers, we must avoid that discourse in the classroom is didactically ambiguous, our strategies should facilitate understanding through clear communication and precise objectives; this provides for ongoing studies and effective planning.

We chose the search for ordinary maps and those differentiated, in different media, due to the ease of access of students to the Internet. On the other hand, we noticed their sympathy for fantastic stories, various games, series and adventure stories, so we decided to unite all the willingness and interest present in them in favor of the teaching of Geography, contributing to them realizing that geographic knowledge is relevant and is at all times in our lives. Soon we just need to sharpen our perception by acquiring an insight into a better understanding of the world, making appreciations on many levels.

Along with the choice of maps and the study of these, in addition to the manufacture of handcrafted maps, new information and discoveries were spontaneously added to the collective discussion, and they were incorporated and reprocessed, promoting a deeper geographical analysis on maps and cartography.

The topics discussed were numerous and, although the project was designed for the 1st year of high school, it can be adjusted for other grades, with a greater or lesser emphasis, depending on the teacher's choice. The acquisition of knowledge will take place directly and indirectly, due to the methodology adopted, the number of classes available and the contentment provoked in the students and the teacher.

The methodological teachings used during the classes aimed at implementing the project contribute to the student developing the fundamental spatial concepts that will supplement him to be a mapper/reader aware of the cartographic language. Thus, the work proposes, as a starting point, the observation, analysis and representation of the student's living space, expanding to more distant spaces, present in literary stories, in film scripts or as individual characteristics, in this case, usual maps used in our daily lives. 
The topics cover the main concepts of Geography and collaborate in the study of geographical space and its compositions between society and nature. In teaching, this Geography was translated by descriptive study of natural and humanized landscapes, in a way dissociated from men's feelings for space. The didactic procedures adopted mainly promote the description and memorization of the elements that make up the landscapes as an observable dimension of the territory and place.

Topics covered:

- reinforce the apprehension of the concepts of space, place, region, territory;

- reinforce the apprehension of the cartographic concepts acquired in the previous series;

- recognize the mapped place as an experience lived by men in a given historical-cultural context;

- understand the advancement of cartographic technology with the knowledge and appropriation of space by man throughout history;

- differentiate heterogeneous map types, recognizing their characteristics;

- recognize cartographic documents: globes, atlases, maps, charts, plants etc;

- differentiate geographical, literary, handcrafted, digital maps.

- $\quad$ to analyze the imaginary and its representations in everyday life;

- recognize that learning takes place through multiple languages;

- $\quad$ associate teaching with possible interests and knowledge of students;

- $\quad$ associate teaching with affection and lucidity;

- reflect on the understanding of belonging to a place and the need to interact with others and other places in the world;

- $\quad$ propose teaching resources and means adapted for teaching-learning in high school, worrying about the level of each year, being attentive to the qualities and characteristics of the students.

In view of this, it is perceived that, in order to capture a certain knowledge, a process of generalization must also take place. In the case of geography teaching, we can associate this generalization with its methodological principles, and obedience to them, which must exist in any study or work, constitute the systematics of Geography and give it the character of science.

Geographic science went through several phases throughout its formation, which reverberated in its method and its object. These implications in their way of perceiving and proceeding in their scientific and teaching practice are closely related to philosophical conceptions, which, in turn, supported the way of perceiving, conceiving and teaching. These currents, throughout their evolution, in a way brought, to the scientific field and teaching of this discipline, ruptures present in their epistemology. 
In the case of Geography, the object of study, now elected by most of the geographical community as geographical space, has a strong relationship with Philosophy and is related to different paradigmatic views, which, in turn, are structured in different philosophical currents, in the case of:

- $\quad$ extension, formulated by Friedrich Ratzel (1844-1904);

- analogy or General Geography, exposed by Karl Ritter (1779-1859) and Paul Vidal de da Blache (1845-1918);

- connection or interaction, presented in particular by Jean Brunhes (1869-1930);

- causality, formulated by Alexander von Humboldt (1769-1859);

- $\quad$ activity, presented by the same Brunhes.

The vision of totality in teaching and discipline provides the conception that knowledge is not made by watertight content, but is procedural. At the same time, Lev Vygotsky (1998, p. 80) discusses the formation of what he calls a conscious concept, associated with possible abstractions, a thought similar to that of Ausubel:

If consciousness means generalization, generalization, in turn, means the formation of a superordered concept that includes the concept given as a specific case. A super-ordered concept implies the existence of a series of subordinate concepts, and also presupposes a hierarchy of concepts of different levels of generality. Thus, the given concept is inserted in a system of general relations. (VYGOTSKY, 1998, p. 116)

Vygotsky (1998) focuses, in his research, on the importance of the individual/society relationship by reiterating that the characteristics that make us human do not present themselves since our birth or occur due to the impositions of the environment. They stem from the bonds built in human and society relations, for once man changes the environment to respond to his survival needs, he ends up profoundly altering himself.

Rudimentary psychological activities existing in the child are transformed with the absorption of culture throughout life, becoming superior psychological activities. Associated with the latter, conscious control of the individual's conduct is formed, as well as its intentionality in actions and its natural daily independence.

Another substantial point mentioned by Vygotsky (1998) is in language as a mediator of social relations, which interferes predominantly in learning, which is continuous but variable, qualitatively speaking. He explains in detail what a child's actual development would be - when their findings are already consolidated and potential development (which refers to those abilities that the child can achieve with the help of another individual); as well as the space between the two levels that was called the 
proximal or potential development zone. In this situation, trials and experiments are crucial, since learning results from communication between similar, joint doing, assays and constant repetition.

Vygotsky's (1998) work is very important for defining what the teaching-learning process is, because by specifying proximal development, he allowed us to measure individual development and, when we plan specific strategies directed at a child or young person, these, each in their own way, could probably thrive in terms of learning. And in this case, the teacher acts as a moderator, collaborating so that the child or the young person can convert his latent capacity into a true growth.

On the value of Vygotsky's studies for teaching, Ivic (2010) instructs:

In this notion of proximal zone, the child's thesis as a social being generates a methodological contribution of great significance, since it focuses on the development of the child in its dynamic and dialectical aspect. Applied to pedagogy, this notion allows us to emerge from the eternal dilemma of education: is it necessary to wait for the child to reach a particular level of development to begin school education, or is it necessary to submit it to a certain education so that it reaches such a level of development? In line with the dialectical ideas of the relationships between learning and development processes that we analyze, Vygotsky adds that the latter is more productive if the child is exposed to new learning, precisely in the proximal development zone. In this area, and in collaboration with the adult, the child can easily acquire what he would not be able to do if he was left to himself. (IVIC, 2010, p.33)

And it also continues, Ivic (2010):

Vygotsky's analysis of the relationship between development and learning, in the case of language acquisition, leads us to define the first model of development: in a natural process of growth of the individual. Learning appears as a way to reinforce this spontaneous process, making available to them the instruments created by culture that expand the intrinsic possibilities of the individual and restructure his mental functions. . (IVIC, 2010, p.20)

With Wallon (2000), we learn to give due relevance to affectivity in the evolution of teachinglearning, which is usually not taken into account in the school environment still very much tied to traditional points of view, in which the student is little heard and has limited autonomy. In Wallonian pedagogy, it is even proposed to distinguish the manifestations of students' behavior, how they express themselves bodily in the face of what is presented to them in the classroom and what effects school practices produce on them, and students will be giving us traces of how they are interacting with teaching practices. And these clues can be used in favor of the students themselves, through methods closer to their particularities.

We believe that affectivity, being present in the pedagogical practices of Geography, can be transferred to this discipline, allowing the student to see it with other eyes. And the educator, from this awareness, can internalize in his daily practice.

As a form of clarification, according to Gratiot-Alfandéry (2010): 
In fact, Wallon offers another valuable contribution to the educational field by describing the methodology he adopts in his investigations. He draws attention to the need to deconstruct the adult-centered look present in observation and research methodologies on child development. With this he warns of the fact that some manifestations of the child, interpreted by the adult's gaze always marked by his own reference - tends to generate postures and build senses often mistaken of what the child demonstrates. (GRATIOT-ALFANDÉRY, 2010, p. 38):

\section{METHODOLOGY}

We emphasize, initially, the application of a diagnostic evaluation for the perception of cartographic concepts acquired by students in previous school years. Later, from it, there was an informal research done by the students on the creation and use of maps over time related to the analysis of the documentary "The History of Maps" (co-production BFC Productions and France 5), which can be spent in class or assisted by students at home through the internet.

This informal research served to stimulate the young person to think about the process of structuring his knowledge and to incorporate his point of view in the graphic and cartographic representations of the different types of space existing. Students were asked to survey maps, from the origin of these, elaboration and use, historical period in which each map was made, technologies employed, among others; there is a likelihood that students will also develop their own maps.

The activity was carried out in pairs, each of which was responsible for bringing to the collective its preliminary investigation on the history of maps, in addition to bringing at least two maps - one usual and the other unusual to the classroom.

It was up to the professor to prepare a relevant pedagogical material, based on the theory of Significant Learning by David Ausubel (2000), and, in a complementary way, the parameters present also in the Historical-Cultural Theory of Lev Vygotsky (1998) and in the Development Theory of Henri Wallon (2000) were used.

Images of different, high-quality maps, made available free of charge, were collected via the internet. Once the maps were chosen, they were printed in color, in size A3 (Figure 1). An exhibition was made in the room to be more easily analyzed by the students, in order to have a collective discussion and, in sequence and through a complementary exercise, the identification of their characteristics. 
Figure 1: Maps printed in size A 3

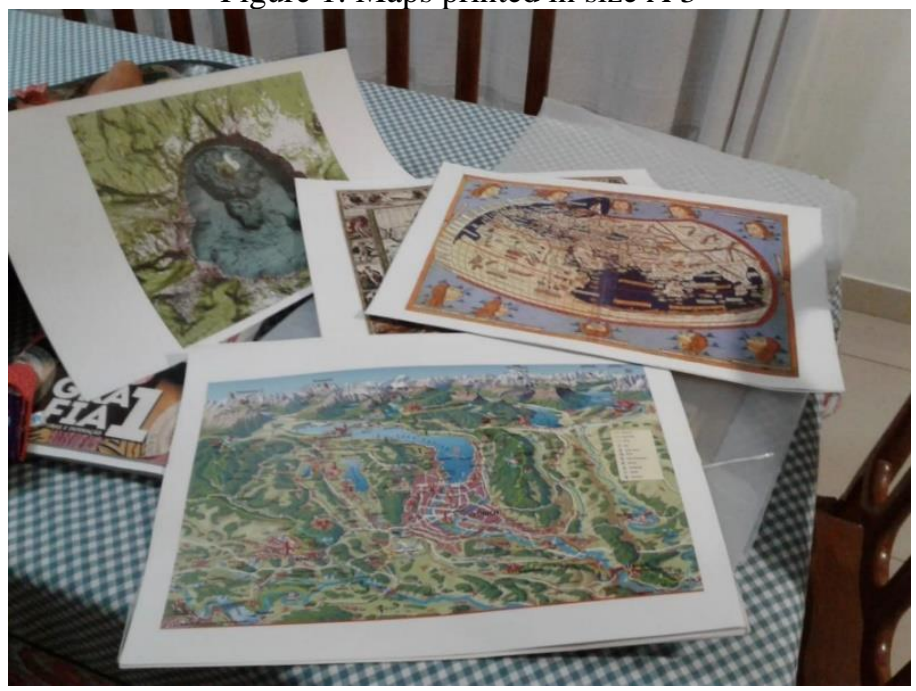

Source: Authors' archive.

In a second moment, there was a debate in the classroom about what was investigated and reflected until then, from the identification of the elements of the geographical space concatenated to the baggage of life brought by the students, to the recognition of the elementary characteristics present in the maps, their organization and the use of the scale.

This unfolding of a spatial scale and everything that concerns him made it possible for the students to be able to interconnect the interpretation of the lived world, transposing it into its representation on maps, giving them meaning. Better to say, the examination of the geographical space in its vicinity was carried out, going from the mere impression of the immediate world to its critical consideration to a greater degree, structuring its knowledge, then conceiving its own drawings/manuscripts. Thus, there was a dialogue between drawing, writing/literature and history exposed in each idealized map.

In possession of these references after drawing up their maps (Figure 2), these were brought together with others researched and printed for collective debate in the classroom: non-normal maps present in literary stories, in film scripts, or with very peculiar characteristics; usual maps used in our daily lives, in order to be naturally recognized by students (road maps, political, demographic, etc.). 
Figure 2: Example of a map drawn up per student

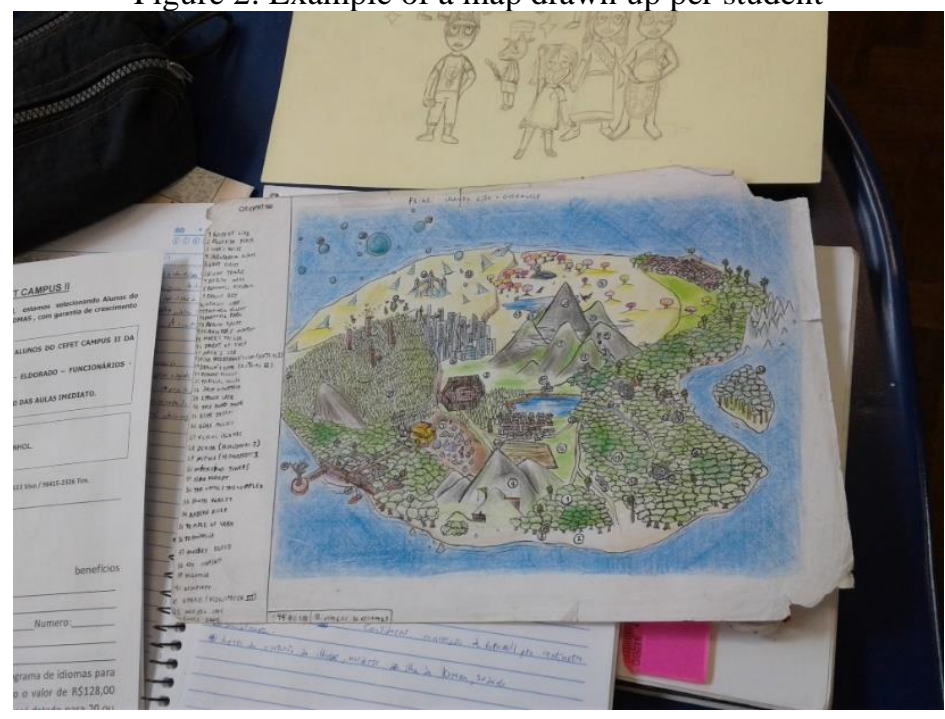

Source: Authors' archive.

The dialogued oral exam performed showed an expansion of the mental representation skills of the students, as well as the understanding about the territories represented there, fictitious or real, and their spatial scales. Therefore, there was a link between research and the production of maps within a historical context of life and also in the fictional/literary environment with the teaching of Cartography.

The display of the maps took place through the installation of rods on the walls of the classroom, with the help of barbistic prosaics, small nails and clothes preachers. This allowed the confrontation between the maps, the verification of their attributes and the reading of the normal and non-normal ones. In addition, there were maps constructed by the students and some examples of technical-cartographic maps resulting from the scientific development of today (Figures 3 and 4).

Figure 3: Analysis of maps in the classroom

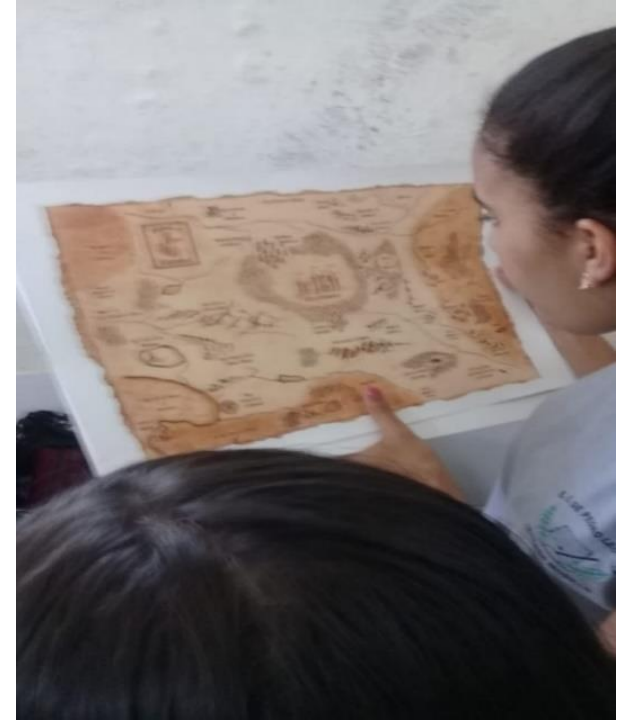

Source: Authors' archive. 
Figure 4: Clothesline in class.

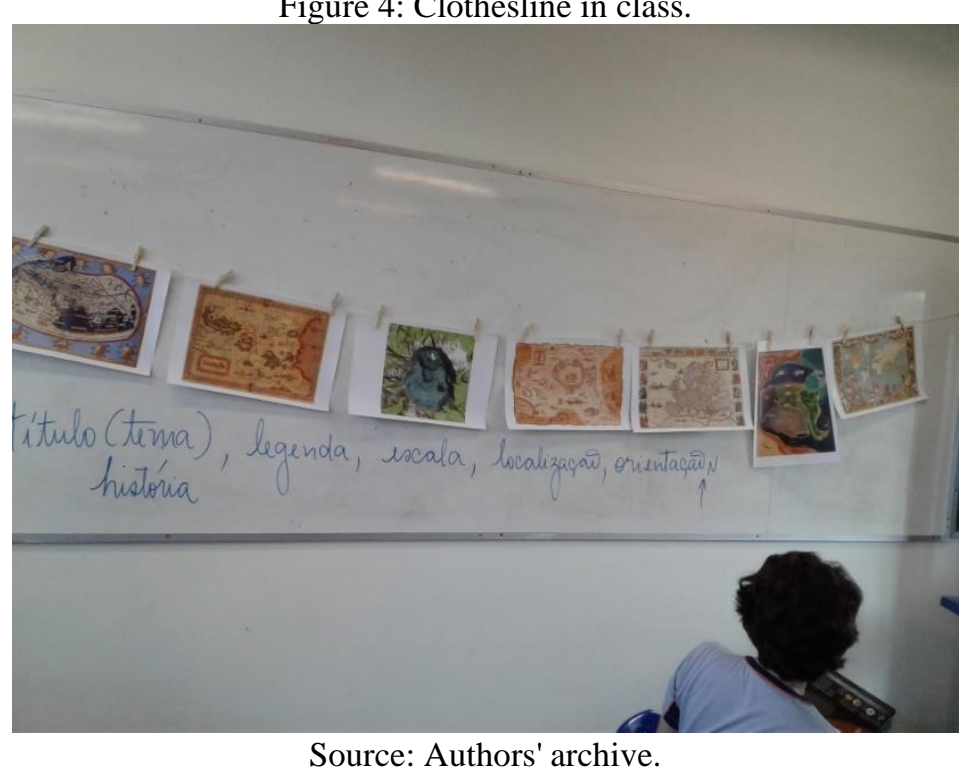

This set of activities presupposes the use of maps as a moderating mechanism of teaching-learning, whether they are found in books, on the Internet and other media, or by students. In this sense, these materials establish a correlation with contents already discussed previously in the room and are means to review and consolidate knowledge.

If the maps are unable to print, the teacher will use creativity to work around the problem: images from different maps can be copied or viewed through slides, movies, for example. The educator can also use a number of devices to boost their classes and whatever tools or materials they use. The important thing is that students can see and then look at the environment in question, compile information, create maps and/or decipher them, make analogies... And that, qualitatively, they are questioned by the mediator about their perceptions in the face of these representative elements of space and can connect them with the principles of geography and, therefore, with their lives.

\section{FINAL CONSIDERATIONS}

This didactic-methodological proposition of teaching in Geography, having Cartography as an instructional route, is not ready, because it is a set of planned procedures that was successful in a context, providing new considerations about the use of maps in the first year of high school, which we judge as an imperative aspect for the deepening of the understanding of geographic space.

There was an understanding of the processes of creation of maps and their functions by the students, as well as a clarity about the degrees of assimilation of space, from the street where one lives to reaching larger scales. In addition, it was perceived as the discernment that reading a book, images or other means of representation of stories (real or fictitious) are susceptible to spatial reproduction, whatever these experiences. 
The use of cartographic tools, in a congruent way with the reality of the student and acting as an attractive means in relation to geography, can lead to a better direction in the pedagogical practice of the teacher, ensuring an authentic learning. 


\section{REFERENCES}

ALMEIDA, R. D. Uma proposta metodológica para a compreensão de mapas geográficos. In: In: ALMEIDA, R. D. Cartografia Escola. São Paulo: Contexto, 2011, p. 145-172.

AUSUBEL, D. P. Aquisição e Retenção de Conhecimentos: uma Perspectiva Cognitiva. Lisboa, Plátano Edições, 2000.

AUSUBEL, D. P., NOVAK, J. D., HANESIAN, H. Psicologia educacional. Tradução Eva Nick. Rio de Janeiro: Interamericana, 1980.

BRASIL, SECRETARIA DE ENSINO FUNDAMENTAL. Parâmetros Curriculares Nacionais: Geografia. Brasília: MEC/SEF, 1998.

CAVALCANTI, L. S. Propostas curriculares de Geografia no ensino: algumas referências de análise. Revista Terra Livre, AGB, n. 14, p. 125-145, jan.-jul., 1999.

GALVÃO, I. Henri Wallon: uma concepção dialética do desenvolvimento infantil. $2^{\mathrm{a}}$ ed. Petrópolis, RJ: Vozes, 2000.

GRATIOT-ALFANDÉRY, H. Henri Wallon. Recife: Fundação Joaquim Nabuco, Editora Massangana, 2010.

IVIC, I.; COELHO, E. P. Lev Semionovich Vygotsky. Recife, Fundação Joaquim Nabuco, Editora Massangana, 2010.

VYGOSTKY. L. S. Pensamento e Linguagem. São Paulo: Livraria Martins Fontes Editora, 1998. 